\title{
Características agronômicas do Panicum maximum cv. “Mombaça” submetido a níveis crescentes de fósforo
}

\author{
Agronomic characteristics of the Panicum maximum cv. Mombaça submitted to increasing levels of \\ phosphorus
}

\author{
Evandro Maia Ferreira ${ }^{\mathrm{I}^{*}}$ Antonio Clementino dos Santos ${ }^{\mathrm{II}}$ Leandro Coelho de Araújo $^{\mathrm{I}}$ \\ Odslei Fagner Ribeiro Cunha'
}

\section{RESUMO}

O objetivo deste experimento foi avaliar o efeito da adição de doses crescentes de $\mathrm{P}_{2} \mathrm{O}_{5}$ sobre a altura do dossel, o número de perfilhos e a produção de matéria seca de folhas e de colmos do capim-Mombaça, em diferentes idades. Foi conduzido um experimento implantado em um Nitossolo Vermelho Eutrófico. O delineamento experimental usado foi o de blocos completos casualizados, com quatro repetições, cinco doses de $\mathrm{P}_{2} \mathrm{O}_{5}\left(30,60,90,120\right.$ e $\left.150 \mathrm{~kg} \mathrm{ha}^{-1}\right)$ e uma testemunha. Para a primeira e segunda coletas, observou-se o efeito linear do fósforo sobre o perfilhamento. Para a terceira e quarta coletas, os dados ajustaram-se ao modelo quadrático. A participação das lâminas foliares na matéria seca da parte aérea diminuiu com as doses de $\mathrm{P}_{2} \mathrm{O}_{5}$. Por outro lado, a participação de colmos aumentou com as doses de $\mathrm{P}_{2} \mathrm{O}_{5}$. A produção de matéria seca (MS) da parte aérea para primeira, segunda e terceira coletas respondeu de forma linear à aplicação de $\mathrm{P}_{2} \mathrm{O}_{5}$ observando-se um aumento estimado de 7 , 15 e $19 \mathrm{~kg} \mathrm{ha}^{-1}$ de $\mathrm{MS}$ por $\mathrm{kg} \mathrm{ha}^{-1}$ de $\mathrm{P}_{2} \mathrm{O}_{5}$, respectivamente. Para a quarta coleta, os dados ajustaram-se ao modelo quadrático de regressão, sendo a máxima produção, $8,3 \mathrm{Mg}$ $\mathrm{ha}^{-1}$ de MS, obtida com a aplicação de $103 \mathrm{~kg} \mathrm{ha}^{-1}$ de $\mathrm{P}_{2} \mathrm{O}_{5}$.

Palavras-chave: matéria seca, perfilhamento, produtividade.

\section{ABSTRACT}

The objective of this experiment was to evaluate the effects of the addition of increasing doses of $\mathrm{P}_{2} \mathrm{O}_{5}$ on the height of the dossal, number of stalks, production of dry matter of leaves and the stems of the Mombaça-grass, in different ages. The experiment was implanted in an Eutrophic Red Nitossol. The experimental designs used were complete randomized block, with four replicates, five levels of $\mathrm{P}_{2} \mathrm{O}_{5}$ (30, $60,90,120$, and $150 \mathrm{~kg}$. ha-1) and a tester. Analyzing the first and second harvest of the pasture the tillering showed positive linear response to the increasing phosphorus levels, for the third and fourth harvest, the data were adjusted to the quadratic model. Increasing $\mathrm{P}_{2} \mathrm{O}_{5}$ doses decreased the leaf lamina fraction of aerial part dry matter, however raised the stems fraction. In the first, second and third harvest, aerial part dry matter production increased linearly $\left(7,15\right.$ and $19 \mathrm{~kg} \mathrm{ha}^{-1}$ of DM for $\mathrm{kg} \mathrm{ha}^{-1}$ of $\mathrm{P}_{2} \mathrm{O}_{5}$, respectively). In the fourth harvest the data were adjusted to the quadratic model of regression, the maximum production ( $8.3 \mathrm{Mg} \mathrm{ha} \mathrm{a}^{-1}$ of DM) was obtained in the application of $103 \mathrm{~kg} \mathrm{ha}^{-1}$ of $\mathrm{P}_{2} \mathrm{O}_{5}$.

Key words: dry matter, tillering, yield.

\section{INTRODUÇÃO}

O estado do Tocantins, com sua vocação para exploração pecuária e com um rebanho bovino de 6.458.832 cabeças (ANUALPEC, 2005), apresenta grande potencial para crescimento nesta atividade, sendo que as pastagens nativas ou cultivadas são a base alimentar da bovinocultura no Estado.

Um dos maiores problemas para o estabelecimento e a manutenção de pastagens nos solos brasileiros é o baixo nível de fósforo (P) disponível aliada à alta capacidade de adsorção desses solos em conseqüência de sua acidez e teores elevados de óxidos de ferro e alumínio (LOBATO et al., 1994).

O desenvolvimento e estabelecimento das espécies forrageiras é limitada pela baixa disponibilidade de P no solo. A deficiência de P causa

'Programa de Pós-graduação em Ciência Animal e Pastagens, Escola Superior de Agricultura "Luiz de Queiroz” (ESALQ/USP). Rua Fernando Febeliano da Costa, 1610, Bairro dos Alemães, 13416-253, Piracicaba, SP, Brasil. E-mail: emferrei@esalq.usp.br. *Autor para correspondência.

IICurso de Zootecnia, Universidade Federal do Tocantins (UFT), Araguaína, TO, Brasil.

"IIUFT, Araguaína, TO, Brasil. 
distúrbios severos ao metabolismo e desenvolvimento das plantas, tais como crescimento lento, pouco perfilhamento e pouco desenvolvimento do sistema radicular, comprometendo a produtividade de plantas forrageiras (WERNER, 1986). Assim, a presença de P (adubação fosfatada) é considerada de vital importância para o estabelecimento de pastagens (CORRÊA \& HAAG, 1993).

Vários estudos têm comprovado a importância da adubação fosfatada para o adequado estabelecimento e a manutenção das pastagens cultivadas nos solos brasileiros. No entanto, as necessidades de requerimentos por nutrientes, para uma mesma espécie forrageira, variam em função das condições edafoclimáticas (temperatura, luminosidade, disponibilidade hídrica, tipo de solo), disponibilidade de outros nutrientes, manejo da adubação (forma, tipo e época de aplicação de fertilizantes) e idade da planta (FONSECA et al., 1988). Assim, o conhecimento das exigências nutricionais limitantes ao crescimento das gramíneas forrageiras para regiões específicas do país é de grande importância para a formação, o manejo e a persistência das pastagens cultivadas (BELARMINO et al., 2003).

A maior parte das forrageiras cultivadas no estado do Tocantins é representada por gramíneas do gênero Brachiaria. No entanto, suas pastagens têm sofrido grande redução com a sucessão dos anos de exploração, sendo que o Panicum maximum cv. "Mombaça" tem sido introduzido nesta região em substituição às pastagens de braquiária. Algumas cultivares de Panicum maximum Jacq. não têm tido sucesso em solos com baixos níveis de fósforo disponível (BERETA et al., 1999). As informações sobre o capim-Mombaça ainda são muito escassas para o Estado do Tocantins, carecendo de mais estudos para determinar suas exigências quanto ao manejo e à fertilidade do solo.

Os solos da região norte do Tocantins, de modo geral, apresentam níveis elevados de acidez e baixo conteúdo de fósforo disponível, devido à intensa ação intempérica, em função das temperaturas e umidade altas, predominantes nessa região.

Diante do exposto, foi objetivo deste trabalho avaliar a influência da adição de doses crescentes de $\mathrm{P}_{2} \mathrm{O}_{5}$ sobre a altura, o número de perfilhos, e a produção de matéria seca de folhas, de colmos, em diferentes idades, implantado em um Nitossolo Vermelho Eutrófico, bem como a participação de folhas e colmos na matéria seca da parte aérea.

\section{MATERIAL E MÉTODOS}

O experimento foi realizado a campo na Fazenda Santa Fé, município de Araguatins, Estado do
Tocantins, no período de dezembro de 2004 a agosto de 2005. O clima da região, de acordo com a classificação de Köppen, é do tipo Aw (quente e úmido), com estação seca de abril a outubro e precipitação pluviométrica média anual de $1.500 \mathrm{~mm}$. Aárea localiza-se na transição entre o bioma Cerrado e Floresta.

O solo da área experimental foi classificado como Nitossolo Vermelho Eutrófico (EMBRAPA, 1999), o qual apresentou a seguinte composição na camada superficial: $\mathrm{pH}=5,3 ; \mathrm{P}=1,5 \mathrm{mg} \mathrm{dm}^{-3} ; \mathrm{K}=117 \mathrm{mg} \mathrm{dm}^{-3}$; $\mathrm{Ca}=21 \mathrm{mmol} \mathrm{kg}^{-1} ; \mathrm{Mg}=9 \mathrm{mmol} \mathrm{kg}{ }^{-1} ; \mathrm{H}+\mathrm{Al}=17 \mathrm{mmol} \mathrm{kg}^{-1}$; $\mathrm{CTC}=50 \mathrm{mmol} \mathrm{kg}^{-1} ; \mathrm{V}=65 \% ; \mathrm{M} . \mathrm{O}=0,9 \mathrm{~g} \mathrm{~kg}^{-1}$, analisado conforme EMBRAPA(1997).

O delineamento experimental utilizado foi em blocos completos casualizados, com cinco tratamentos, uma testemunha e quatro repetições, totalizando 24 unidades experimentais, com $9 \mathrm{~m}^{2}$. Os tratamentos constituíram das doses 30, 60, 90, 120 e $150 \mathrm{~kg} \mathrm{ha}^{-1}$ de $\mathrm{P}_{2} \mathrm{O}_{5}$. Todas as parcelas receberam adubação básica com 0,5 Mg de calcário dolomítico ha-1 (PRNT de 90\%) para fornecimento de Ca e Mg e $45 \mathrm{~kg} \mathrm{ha}^{-1}$ de $\mathrm{N}$, não sendo realizada adubação com potássio em virtude de já existir uma quantidade satisfatória de $\mathrm{K}_{2} \mathrm{O}$ no solo.

$\mathrm{O}$ adubo fosfatado foi aplicado em sulcos, abertos em linhas, espaçadas em $0,4 \mathrm{~m}$, com posterior incorporação ao solo, a uma profundidade de $0-10 \mathrm{~cm}$. Em seguida, realizou-se a semeadura a lanço sobre o adubo, utilizando-se $7 \mathrm{~kg} \mathrm{ha}^{-1}$ de sementes puras viáveis de Panicum maximum cv. "Mombaça".

Quarenta e nove dias após a germinação, foi realizado um corte de uniformização da forrageira a dez centímetros do solo, de forma manual, utilizandose cutelos. Na ocasião, efetuou-se a adubação basal com nitrogênio em cobertura. A partir desta data, em quatro períodos de coletas aos 14, 21, 28 e 35 dias após o corte de uniformização, determinou-se. Altura do dossel, o número de perfilhos e realizou-se coleta de biomassa da forrageira.

Para a medida da altura do dossel, foram escolhidos cinco pontos aleatórios por unidade experimental e utilizando-se uma fita métrica, graduada em centímetros, mediu-se da base da planta até a curvatura das folhas que representavam a altura média do dossel.

Para quantificar o número de perfilhos, produção e composição morfológica da forragem em cada corte, por unidade experimental, utilizou-se uma área de $0,25 \mathrm{~m}^{2}$, que foi escolhida ao acaso. Após a contagem do número de perfilhos existente na área do quadrado, estes foram cortados a $10 \mathrm{~cm}$ do solo e a massa fresca de forragem for pesada e subamostrada. A subamostra de aproximadamente $200 \mathrm{~g}$ foi separada manualmente em seus constituintes morfológicos [folha 
(lâminas foliares) e colmos (colmo + bainha)] os quais foram levados para secagem em estufa de circulação e renovação de ar à temperatura de $65^{\circ} \mathrm{C}$ até peso constante. O peso seco da subamostra e a sua composição morfológica foram extrapolados para a amostra.

Os valores de altura de plantas, o número de perfilhos, a produção de matéria seca de folhas e a produção de matéria seca de colmos e da parte aérea foram utilizados para se avaliar os efeitos dos tratamentos. Os dados foram submetidos à análise de regressão e teste $\mathrm{F}$ ao nível de 5\% de probabilidade. Utilizou-se o programa estatístico ESTAT para obtenção das equações de regressão e teste t para os graus de significância dos coeficientes de regressão.

\section{RESULTADOS E DISCUSSÃO}

Altura do dossel em função dos níveis de $\mathrm{P}_{2} \mathrm{O}_{5}$ Os dados de altura do dossel estão apresentados na figura 1a. Para a primeira coleta, não houve efeito significativo das doses de $\mathrm{P}_{2} \mathrm{O}_{5}$ sobre a altura do dossel do capim-Mombaça, com valor médio de $36,21 \mathrm{~cm}$. No entanto, houve efeito quadrático para segunda, terceira e quarta coletas, sendo as alturas máximas obtidas iguais a 86,67; 104,28 e 132,89cm, que corresponderam às doses de 127; 118 e $124 \mathrm{~kg} \mathrm{ha}^{-1} \mathrm{de}$ $\mathrm{P}_{2} \mathrm{O}_{5}$, respectivamente. Resultados semelhantes foram encontrados por BELARMINO et al. (2003), quando estudaram o efeito de doses de $\mathrm{P}_{2} \mathrm{O}_{5}$ e de $\mathrm{N}$ sobre o crescimento de perfilhos do capim-Tanzânia em três períodos de corte. Os autores observaram que não houve efeito significativo das doses de $\mathrm{P}_{2} \mathrm{O}_{5}$ sobre a altura de perfilhos no corte de nivelamento da forrageira, realizado aos 68 dias de idade, havendo, no entanto, efeito significativo tanto para o segundo quanto para o terceiro corte, quando a forrageira estava com 48 dias em crescimento de rebrotação.

Número de perfilho em função dos níveis de $\mathrm{P}_{2} \mathrm{O}_{5}$

Observou-se efeito significativo das doses de $\mathrm{P}_{2} \mathrm{O}_{5}$ sobre o número de perfilhos do capimMombaça em todos os períodos de coleta estudados (Figura 1b).

Para a primeira e segunda coletas, verificouse efeito linear crescente do fósforo sobre o perfilhamento, ocorrendo um aumento de 0,86 e 1,01 perfilhos $\mathrm{m}^{-2}$ por $\mathrm{kg}$ de $\mathrm{P}_{2} \mathrm{O}_{5}$ aplicado $\mathrm{ha}^{-1}$, respectivamente. Para a terceira e quarta coletas, os dados de número de perfilhos em função das doses de $\mathrm{P}_{2} \mathrm{O}_{5}$ ajustaram-se melhor ao modelo quadrático, sendo o máximo perfilhamento obtido igual a 411,02 e 485,77 perfilhos $\mathrm{m}^{-2}$, que correspondeu à aplicação de 135 e
$110 \mathrm{~kg} \mathrm{ha}^{-1}$ de $\mathrm{P}_{2} \mathrm{O}_{5}$, respectivamente, ocorrendo um decréscimo na emissão de perfilhos a partir destas doses.

O aumento do número de perfilhos com a aplicação de fósforo é condizente com as informações da literatura. GUSS et al. (1990), trabalhando em casa de vegetação, avaliaram as doses 45, 90, 180, 360 e $720 \mathrm{mg} \mathrm{dm}^{-3}$ de $\mathrm{P}$ sobre o estabelecimento de quatro cultivares de Braquiária e observaram que o número estimado de perfilhos correspondente a $90 \%$ do perfilhamento máximo foi de 28; 52; 69 e 70 perfilhos vaso $^{-1}$ obtidos com aplicação de 309; 282; 335 e 318mg $\mathrm{dm}^{-3} \mathrm{de}$ P, para a B. brizantha, B. decumbens, B. ruziziensis e $\boldsymbol{B}$. humidicola, respectivamente. Sendo o número médio de perfilhos emitidos por essas espécies, quando submetida à menor dose $\left(45 \mathrm{mg} \mathrm{dm}^{-3}\right.$ de P) igual a 6; 17; 15 e 22 perfilhos vaso ${ }^{-1}$, reafirmando assim o efeito da adubação fosfatada sobre o perfilhamento das forrageiras.

Produção de matéria seca de lâminas foliares (MSF) em função dos níveis de $\mathrm{P}_{2} \mathrm{O}_{5}$

Os dados de produção de MSF em função das doses de $\mathrm{P}_{2} \mathrm{O}_{5}$ estão apresentados na figura 2a. Para as três primeiras coletas, verificou-se aumento linear de produção de MSF em função do aumento da dose de $\mathrm{P}_{2} \mathrm{O}_{5}$. Para a quarta coleta, observou-se efeito quadrático, havendo um aumento estimado na produção de MSF até a dose de $105 \mathrm{~kg} \mathrm{ha}^{-1}$ de $\mathrm{P}_{2} \mathrm{O}_{5}$. Observando-se as respostas de produção de matéria seca de folhas com as doses crescentes de $\mathrm{P}_{2} \mathrm{O}_{5}$, verificou-se um comportamento contrário ao da participação das folhas na matéria seca da parte aérea (Figura 3a). Isso se deve ao rápido crescimento vegetativo da planta no período estudado, assim, com o aumento da produção de matéria seca de folhas em função das doses crescentes de fósforo, a produção de colmos foi aumentada, acarretando uma diminuição da participação das lâminas foliares na matéria seca da parte aérea. No entanto, SANTOS et al. (1999) verificaram na cv. "Tanzânia” que a participação da matéria seca das lâminas foliares aumentou com o crescimento da parte aérea, o que pode ser atribuído à reduzida taxa de alongamento dos colmos para esta cultivar no período estudado.

Quanto ao tipo de matéria seca, é importante que grande parte seja representada pelas folhas, já que estas são as responsáveis pelo melhor valor nutritivo das forrageiras. No entanto, existe uma correlação negativa entre a relação folha/colmo e a produção de matéria seca da parte aérea, havendo uma redução na produção de matéria seca da parte aérea à medida que 

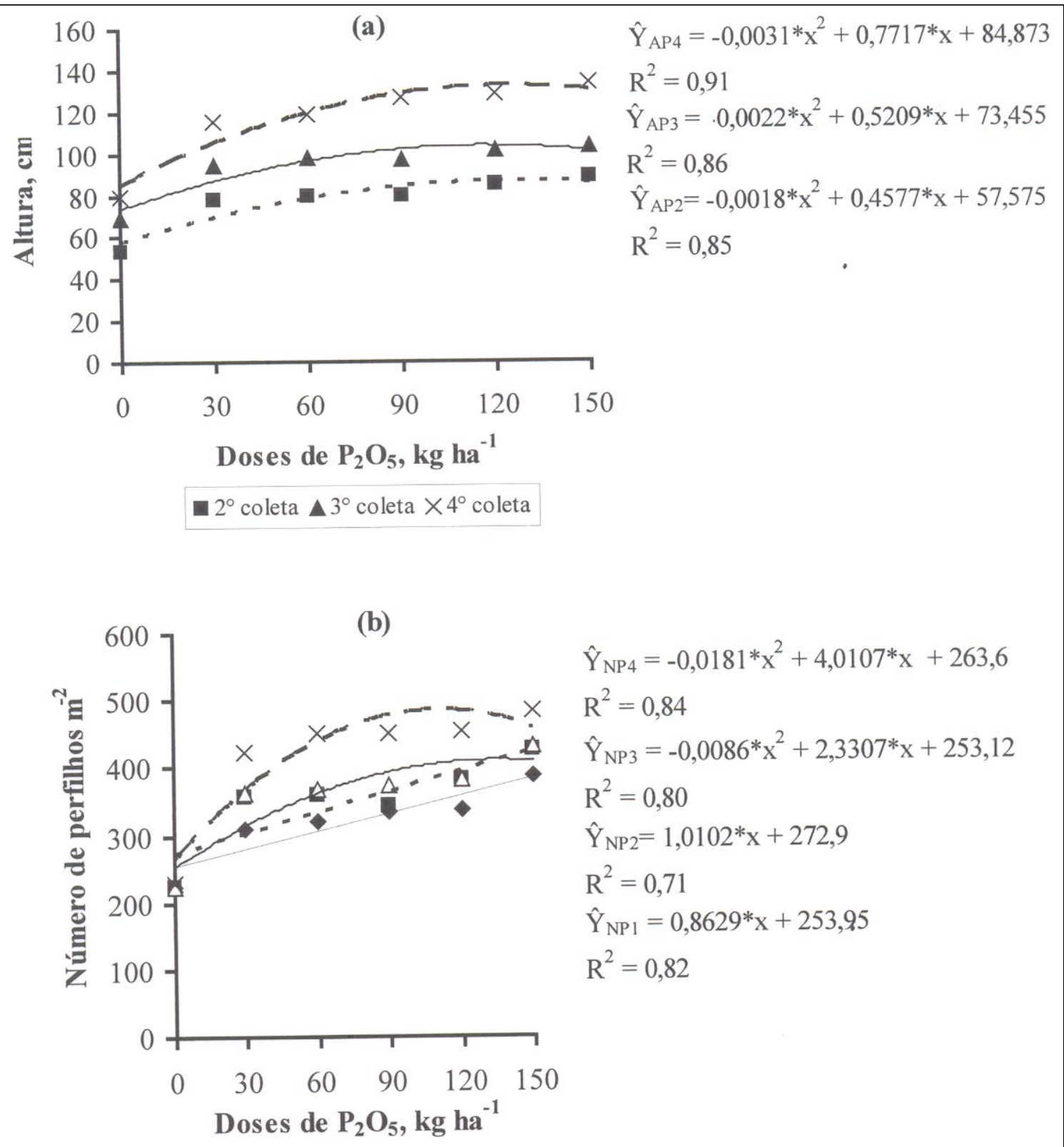

\section{$1^{\circ}$ coleta $2^{\circ}$ colet $\Delta 3^{\circ}$ coleta $\times 4^{\circ}$ coleta}

Figura 1 - Altura do dossel (a) e número de perfilhos $\mathrm{m}^{-2}$ (b), de Panicum maximum cv. "Mombaça”, na primeira (Y), segunda $\left(\mathrm{Y}_{2}\right)$, terceira $\left(\mathrm{Y}_{3}\right)$ e quarta $\left(\mathrm{Y}_{4}\right)$ coletas, em função das doses de $\mathrm{P}_{2} \mathrm{O}_{5},{ }^{*} \mathrm{P}<0,05$.

a relação folha/colmo aumenta (HERLING et al., 2000). Isto aponta para a necessidade de se encontrar um ponto de equilíbrio em que se consiga aliar produção e qualidade da matéria seca produzida.

Produção de matéria seca de colmos (MSC) em função dos níveis de $\mathrm{P}_{2} \mathrm{O}_{5}$

Os dados relativos à produção de MSC encontram-se na figura $2 \mathrm{~b}$. Para as três primeiras coletas, observou-se que a produção de MSC aumentou linearmente em função do aumento da dose de $\mathrm{P}_{2} \mathrm{O}_{5}$. Para a quarta coleta, o modelo de regressão polinomial quadrática foi o que melhor se ajustou aos dados e também indicou um aumento na produção até a dose de $103 \mathrm{~kg} \mathrm{ha}^{-1}$ de $\mathrm{P}_{2} \mathrm{O}_{5}$, sendo que $90 \%$ da produção máxima para esta coleta (2,97 Mg ha ${ }^{-1}$ de MS) foi obtida com a aplicação de $70 \mathrm{~kg} \mathrm{ha}^{-1}$ de $\mathrm{P}_{2} \mathrm{O}_{5}$. Este aumento significativo na produção de $\mathrm{MSC}^{2}$ em função do 


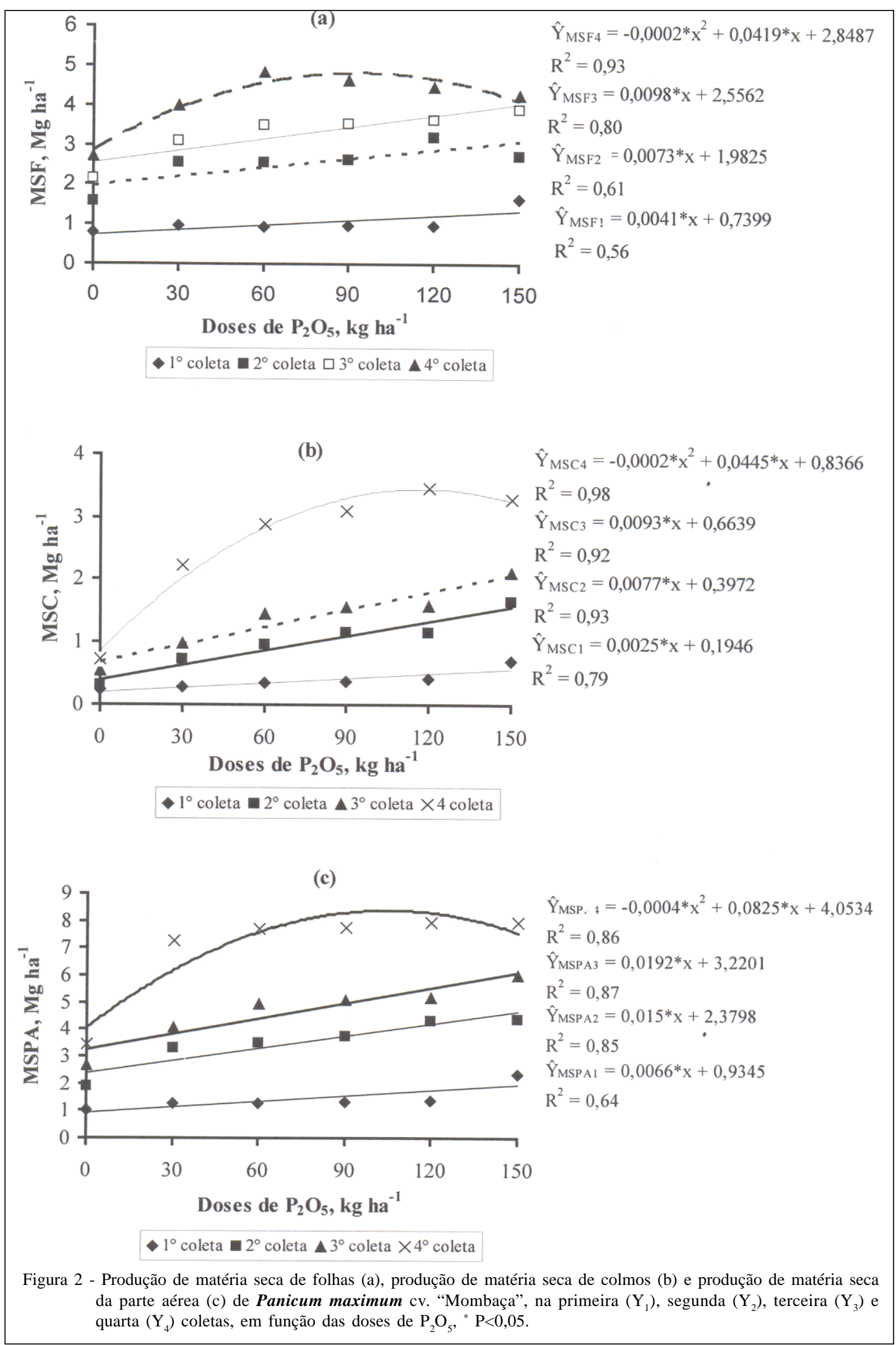

Ciência Rural, v.38, n.2, mar-abr, 2008. 

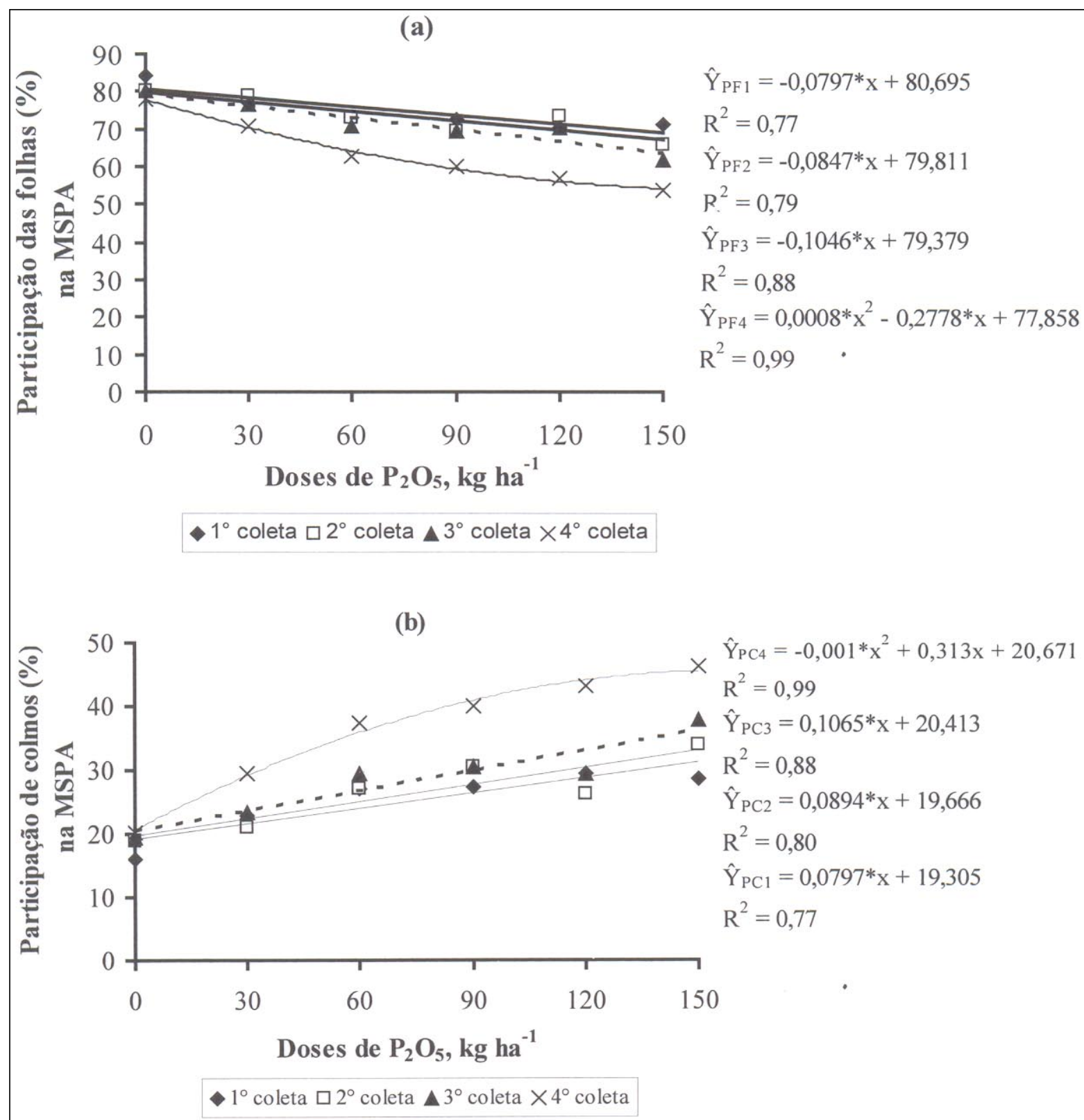

Figura 3 - Participação da matéria seca de folhas (\%) (a) e participação da matéria seca de colmos (\%) (b) na matéria seca da parte aérea (MSPA) de Panicum maximum cv. "Mombaça", na primeira $\left(\mathrm{Y}_{1}\right)$, segunda $\left(\mathrm{Y}_{2}\right)$, terceira $\left(\mathrm{Y}_{3}\right)$ e quarta $\left(\mathrm{Y}_{4}\right)$, coletas, em função das doses de $\mathrm{P}_{2} \mathrm{O}_{5},{ }^{*} \mathrm{P}<0,05$.

aumento de $\mathrm{P}$ também foi observado por FORNI et al. (2000), ao estudar diferentes estratégias de adubação com NPK na produção de matéria seca das gramíneas forrageiras Tanzânia e Mombaça.

Produção de matéria seca da parte aérea (MSPA) em função dos níveis de $\mathrm{P}_{2} \mathrm{O}_{5}$

Os dados de produção de MSPA estão apresentados na figura 2c. Observa-se que para as três primeiras coleta, houve um aumento linear na produção de MSPA em função do aumento da dose de $\mathrm{P}_{2} \mathrm{O}_{5}$. Estes resultados estão de acordo com os encontrados por ROSSI \& MONTEIRO (1999), que verificaram efeito significativo das doses crescentes de fósforo em solução nutritiva na produção de matéria seca dos capins Brachiaria brizantha e Panicum maximum cv. "Colonião", mantendo um aumento linear de produção com o aumento das doses de fósforo.

Para a quarta coleta, o modelo de regressão polinomial quadrática foi o que melhor se ajustou aos 
dados, sendo a produção máxima para esta coleta (8,3Mg ha-1 de MS) obtida com a aplicação de $103 \mathrm{~kg}$ ha ${ }^{-1}$ de $\mathrm{P}_{2} \mathrm{O}_{5}$, sendo que $90 \%$ da produção de MSPA foi obtida com a aplicação de $57 \mathrm{~kg} \mathrm{ha}^{-1}$ de $\mathrm{P}_{2} \mathrm{O}_{5}$. Comparando este resultado com o tratamento testemunha (sem adição de $\mathrm{P}_{2} \mathrm{O}_{5}$ ), com produção estimada em 4,05 $\mathrm{Mg} \mathrm{ha}^{-1}$ de MS, observou-se aumento de $105 \%$ na produção de MSPA, sendo que $83 \%$ deste aumento foi obtido com a aplicação de $57 \mathrm{~kg} \mathrm{ha}^{-1}$ de $\mathrm{P}_{2} \mathrm{O}_{5}$.

Participação da matéria seca de lâminas foliares (MSF) na matéria seca da parte aérea (MSPA) em função dos níveis de $\mathrm{P}_{2} \mathrm{O}_{5}$

Os dados da participação da MSF na MSPA estão apresentados na figura 3a. Para a primeira coleta, verificou-se efeito quadrático decrescente da participação da MSF na MSPA em função do aumento da dose de $\mathrm{P}_{2} \mathrm{O}_{5}$. Para as demais coletas, houve uma redução linear da participação da MSF na MSPA com as doses maiores de $\mathrm{P}_{2} \mathrm{O}_{5}$ sendo estes resultados concordantes com os encontrados por RODRIGUES \& ROSA (2004), que também avaliaram a participação da matéria seca das folhas e dos colmos na matéria seca da parte aérea do capim-Tanzânia.

Participação da matéria seca de colmos (MSC) na matéria seca da parte aérea (MSPA) em função dos níveis de $\mathrm{P}_{2} \mathrm{O}_{5}$

Os dados referentes à participação da MSC na MSPA em função das doses de $\mathrm{P}_{2} \mathrm{O}_{5}$ estão apresentados na figura 3b. Para as três primeiras coletas, verificou-se aumento linear da participação de MSC na MSPA. Para a quarta coleta, houve efeito quadrático.

Comparando-se as figuras 3a e 3b, observase que a participação das folhas e dos colmos é complementar no percentual de participação na MSPA. Conforme descrito anteriormente, enquanto a participação de colmos aumentou em função do aumento das doses de $\mathrm{P}_{2} \mathrm{O}_{5}$, a participação de folhas diminuiu, evidenciando um maior acúmulo de matéria seca de colmo em relação à de folhas com o aumento do P, que também foi observado por RODRIGUES \& ROSA (2004), em seu experimento com capim-Tanzânia.

\section{CONCLUSÕES}

A aplicação de fósforo foi eficiente em aumentar a produção de matéria seca da parte aérea do capim-Mombaça até a dose de $103 \mathrm{~kg} \mathrm{ha}^{-1}$ de $\mathrm{P}_{2} \mathrm{O}_{5}$ no quarto período de coleta, apresentando aumento linear de produção nas três primeiras coletas. Houve alteração na composição morfológica das plantas (relação folha:colmo), com aumento da participação de colmos em relação à participação de lâmina foliares na matéria seca da parte aérea, em resposta as doses crescentes de fósforo.

\section{REFERÊNCIAS}

ANUALPEC-2005. Anuário brasileiro de pecuária. São Paulo: FNP Agro Informativo, 2005. 340p.

BELARMINO, M.C.J. et al. Altura de perfilho e rendimento de matéria seca de capim - Tanzânia em função de diferentes doses de superfosfato simples e sulfato de amônio. Ciência Agrotécnica, v.27, n.4, p.879-885, 2003.

BERETTA, L.G.R. et al. Morfogênese foliar e taxas de crescimento de pastagem de Panicum maximum cv. Tanzânia-1 em solo dos Cerrados. In: REUNIÃO ANUAL DA SOCIEDADE BRASILEIRA DE ZOOTECNIA, 36., 1999, Porto Alegre. Anais... Porto Alegre: SBZ, 1999. (Resumo, 130).

CORRÊA, L.A.; HAAG, H.P. Níveis críticos de fósforo para o estabelecimento de gramíneas forrageiras em Latossolo Vermelho-Amarelo, álico: II Experimento de Campo. Scientia Agrícola, v.50, p.109-116, 1993.

EMPRESA BRASILEIRA DE PESQUISA AGROPECUÁRIA EMBRAPA, Centro Nacional de Pesquisa de Solos. Sistema Brasileiro de Classificação de Solos. Rio de Janeiro: EMBRAPA, 1999. 412p.

EMPRESA BRASILEIRA DE PESQUISA AGROPECUÁRIA EMBRAPA. Manual de métodos de análise de solo. 2.ed. EMBRAPA, Rio de Janeiro, 1997. 212p.

FONSECA, D.M. et al. Níveis críticos de fósforo em amostras de solos para o estabelecimento de Andropogon gayanus, Brachiaria decumbens e Hyparrhenia rufa. Revista Brasileira de Ciência do Solo, n.12, p.49-58, 1988.

FORNI, S. et al. Efeito de estratégias de adubação com NPK sobre a produção, qualidade e estrutura dos cultivares Tanzânia e Mombaça de Panicum maximum Jacq. In: REUNIÃO ANUAL DA SOCIEDADE BRASILEIRA DE ZOOTECNIA, 37., 2000, Viçosa, MG. Anais... Viçosa: SBZ, 2000. Resumo 0702. CDROM.

GUSS, A. et al. Exigência de fósforo para o estabelecimento de quatro espécies de Brachiaria em solos com características físicoquímicas distintas. Revista da Sociedade Brasileira de Zootecnia, v.19, n.4, p.278-289, 1990.

HERLING, V.R. et al. Tobiatã, Tazânia e Mombaça. In: PEIXOTO, A.M. et al. (Eds.). In: SIMPÓSIO SOBRE MANEJO DA PASTAGEM, 17., 2000, Piracicaba. Anais... Piracicaba: FEALQ, 2000. p.21-64.

LOBATO, E. et al. Adubação fosfatada em pastagens. In: PEIXOTO, A.M. et al. Pastagens: fundamentos da exploração racional. 2.ed. Piracicaba, FEALQ, $1994 . \quad$ p.155188.

RODRIGUES, J.F.; ROSA, B. Participação da massa seca de folhas e hastes do capim - Tanzânia quando adubado com doses 
crescentes de fósforo em um Latossolo Vermelho distrófico. Ciência Animal Brasileira, v.5, n.4, p.187-194, 2004.

ROSSI, C.; MONTEIRO, F.A. Doses de fósforo, épocas de coleta e o crescimento e diagnose nutricional nos capins braquiária e colonião. Scientia Agrícola, v.56, n.4. p.11011110, 1999.
SANTOS, P.M. et al. Efeito da freqüência de pastejo e da época do ano sobre a produção e a qualidade em Panicum maximum cvs. "Tanzânia” e "Mombaça". Revista Brasileira de Zootecnia, v.28, n.2, p.244-249, 1999.

WERNER, J.C. Adubação de pastagens. Nova Odessa: Instituto de Zootecnia, 1986. 49p. (Instituto de Zootecnia, Boletim Técnico, 18). 